\title{
Catalysis in Flow: Au-Catalysed Alkylation of Amines by Alcohols
}

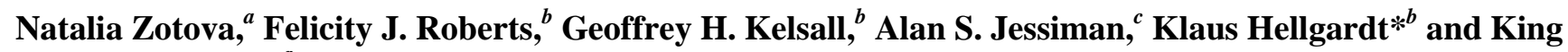 \\ Kuok (Mimi) Hii ${ }^{a}$
}

\author{
Received (in XXX, XXX) Xth XXXXXXXXX 200X, Accepted Xth XXXXXXXXX 200X \\ ${ }_{5}$ First published on the web Xth $X X X X X X X X X 200 X$ \\ DOI: $10.1039 / b 000000 x$
}

\begin{abstract}
By using a greater reaction space afforded by a flow reactor, commercially available $\mathrm{Au} / \mathrm{TiO}_{2}$ can be used for highly selective direct alkylation of amines by alcohols, without the need for an inert atmosphere or base. A brief survey of substrates includes the alkylation of aromatic, aliphatic and 10 chiral amines by a number of primary and secondary alcohols, in high yields and selectivity. The synthesis of Piribedil, a drug used in the treatment of Parkinson's disease, can be achieved in a single synthetic operation without need for column chromatography. Mechanistic aspects of the reaction were revealed through modelling of reaction profiles, and the origin of selectivity is attributed to the accessibility of high temperature. The presence of water was found to be crucial

15 for catalyst activity.
\end{abstract}

\section{Introduction}

The ability to construct increasingly complex molecular structures is a key challenge for organic synthesis, fuelling the demand for synthetic methodologies that can deliver 20 considerable step-economy and high efficiency. ${ }^{1,2}$ Concurrently, the overall sustainability of a chemical process is important for it to be adopted on an industrial scale. This involves issues such as atom-economy, E-factors and selectivity, which ultimately governs economical and 25 environmental costs of chemical production. ${ }^{3}$

Alcohol activation for nucleophilic substitution is frequently used for the preparation of fine chemicals and active pharmaceutical ingredients (APIs), where there is an urgent need for better methodologies. The direct nucleophilic 30 substitution of an alcohol does not occur easily, and generally requires replacement of the $\mathrm{OH}$ by a better leaving group, e.g. halides or $\mathrm{OSO}_{2} \mathrm{R}$. In the pharmaceutical industry, it has been estimated that $64 \%$ of all nitrogen substitution reactions are alkylations. ${ }^{4}$ These reactions are very often difficult to 35 control, due to significant side reactions (over-alkylation or competitive elimination), as well as practical limitations, particularly safety and disposal issues associated with the use of mutagenic alkylating reagents.

An alternate strategy is to employ a catalyst to oxidise an 40 alcohol to a reactive carbonyl compound, which condenses with the amine to form an imine, before it is reduced to the amine (Scheme 1). The redox steps can be achieved using a catalyst to transfer $\mathrm{H}_{2}$ from the alcohol to the imine via metalhydride intermediates ('borrowing hydrogen'). ${ }^{5}$ Perhaps 45 unsurprisingly, metal complexes that are also known to effect reversible dehydrogenation of alcohols (transfer hydrogenation catalysts) have been studied extensively in this context. Accordingly, homogeneous $\mathrm{Ru}$ and Ir catalysts are the most prevalent and effective. ${ }^{5,6}$ Some $\mathrm{Cu}$ and $\mathrm{Fe}$ catalysts 50 have been reported to be effective, however, up to 1 equivalent of base is required. ${ }^{7-9}$ In terms of practicality, heterogeneous catalysts are much more attractive, as they can be easily separated from the product stream. In this regard, $\mathrm{Ru}(\mathrm{OH})_{\mathrm{x}} / \mathrm{TiO}_{2}$ was found to have the widest applicability, 55 including the preparation of highly substituted amines from urea, ${ }^{10,11}$ and the alkylation of (hetero)aromatic amines. ${ }^{12}$ The scope of first-row transition metal catalysts $(\mathrm{Cu}, \mathrm{Fe})$ appears to be limited to certain substrates, such as activated benzyl alcohols or aromatic amines. ${ }^{13-15}$ More recently, a ${ }_{60}$ heterogeneous $\mathrm{Ag} / \mathrm{Mo}$ oxide catalyst has been shown to be effective for the alkylation of a number of aromatic amines, carboxamides and sulfonamides. However, the system required $20-40 \mathrm{~mol} \%$ of base $(t-\mathrm{BuOK}$ for the alkylation of amines), hence requiring column chromatography for product 65 purification. ${ }^{16}$

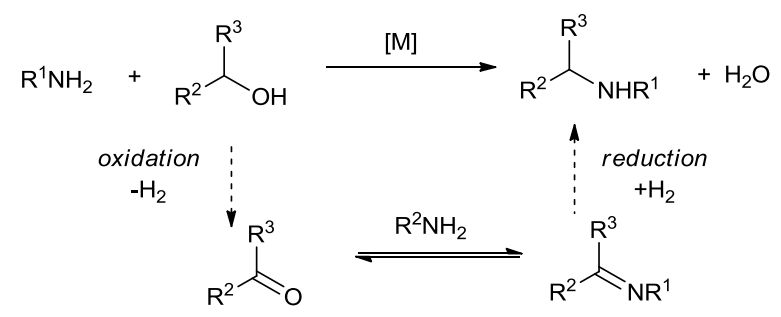

Scheme 1 Direct alkylation of an amine by an alcohol by sequential redox processes.

Heterogeneous gold catalysts are known to be highly 70 effective for the selective oxidation of alcohols ${ }^{17}$ as well as the hydrogenation of aldehydes, ketones and imines. ${ }^{18}$ Thus, there have been several attempts to utilise heterogeneous gold catalysts for the direct alkylation of amines by alcohols. Using benzyl alcohol (1a) and aniline (1b) as typical model 75 substrates (Scheme 2), initial studies largely produced the intermediate imine $\mathbf{3}$ as a major product (Table 1, entries 1 and 2), which was produced exclusively if the reaction was performed under an $\mathrm{O}_{2}$ atmosphere (entries 3 and 4). More recently, the catalytic activity of $\mathrm{Au} / \mathrm{TiO}_{2}$ was re-examined 80 under 5 atm of $\mathrm{N}_{2}$ in an autoclave. In this case, very high selectivity was achieved only by using Au catalyst of very small particle size (entry 5 vs entry 6 ). 


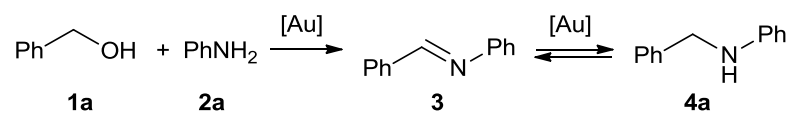

Scheme 2 Model reaction: alkylation of aniline by benzyl alcohol.

Table 1 Reported Au-catalysed reactions between benzyl alcohol (1a) and aniline (2a).

\begin{tabular}{|c|c|c|c|c|}
\hline Entry & {$[\mathrm{Au}]$} & 1a:2a, conditions & Conversion ${ }^{a} / \%$ & 3:4a \\
\hline 1 & $\mathrm{Au} / \mathrm{TiO}_{2}$ & $\begin{array}{c}\text { 1:1, } \mathrm{Cs}_{2} \mathrm{CO}_{3} \text {, toluene, } \mathrm{N}_{2}, \\
110^{\circ} \mathrm{C}\end{array}$ & $>99$ & $22: 15^{b}$ \\
\hline 2 & $\mathrm{Au} / \mathrm{MgO}$ & $1: 3, \mathrm{PhCF}_{3}, \mathrm{~N}_{2}, 180^{\circ} \mathrm{C}$ & 93 & $49: 38^{c}$ \\
\hline 3 & $\mathrm{Au} / \mathrm{HDP}^{d}$ & $1: 1, \mathrm{O}_{2}$, toluene, $60^{\circ} \mathrm{C}$ & 99 & $>99: 1$ \\
\hline 4 & $\mathrm{Au} / \mathrm{TiO}_{2}$ & $\begin{array}{l}1: 1, \mathrm{O}_{2}, \mathrm{CH}_{3} \mathrm{OK}(10 \\
\mathrm{mol} \%), \mathrm{CH}_{3} \mathrm{OH} \text {, r.t. }\end{array}$ & 7 & 99:1 \\
\hline 5 & $\mathrm{Au} / \mathrm{TiO}_{2}-\mathrm{VS}^{e}$ & $\begin{array}{c}1: 1,5 \mathrm{~atm} . \mathrm{N}_{2}, 120^{\circ} \mathrm{C}, \\
\text { toluene }\end{array}$ & $>99$ & $7.5: 92^{f}$ \\
\hline 6 & $\mathrm{Au} / \mathrm{TiO}_{2}{ }^{g}$ & $\begin{array}{c}1: 1,5 \mathrm{~atm} . \mathrm{N}_{2}, 120^{\circ} \mathrm{C}, \\
\text { toluene }\end{array}$ & 71 & $6: 64^{h}$ \\
\hline
\end{tabular}

$5{ }^{a} \mathrm{GC}$ conversions based on alcohol. ${ }^{b}$ Product mixture contained $\mathrm{PhCHO}$ and $\mathrm{PhCO}_{2} \mathrm{Bn}$ side products. ${ }^{c}$ Product mixture contained benzene and toluene side products. ${ }^{d} \mathrm{HDP}:$ Hydroxyapatite. ${ }^{e}$ Mean particle size $\sim 1.8$ nm. ${ }^{f}<0.5 \%$ 'others'. ${ }^{g}$ Obtained from WGC, mean particle size , $~ 3.2 \mathrm{~nm}$. ${ }^{h} 1 \%$ 'others'.

\section{Results and Discussion}

\section{Description of the flow system}

Previously, we have demonstrated the advantages of using a continuous flow reactor for the catalytic oxidation of alcohols 15 by $\mathrm{O}_{2} \cdot{ }^{24}$ Using a small packed bed of heterogeneous catalyst (70 x $4 \mathrm{~mm})$, reactions can be performed safely at elevated temperature and pressures, while precise control of reaction parameters ensures reproducibility and a high space-time yield. Herein, we will demonstrate a successful application of 20 the flow system to gold-catalysed alkylation of amines by alcohols, which can be achieved under highly practical and atom-economical conditions.

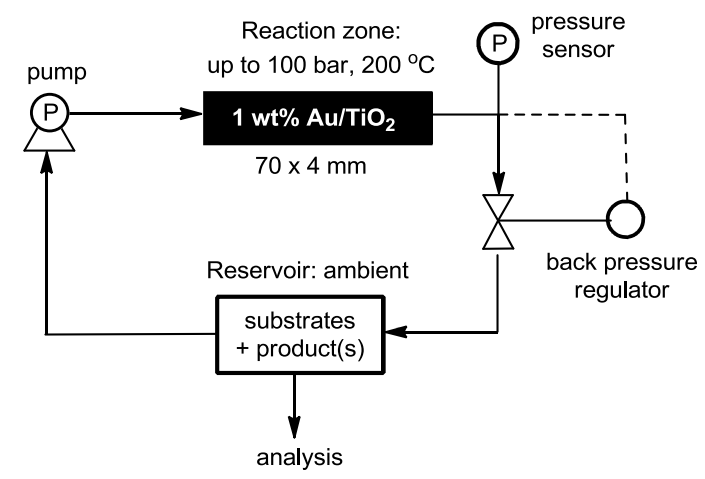

Fig. 1 Configuration of the flow reactor (continuous recycle mode).

25 Using commercially available $\mathrm{Au} / \mathrm{TiO}_{2}$ as catalyst, the reaction between model substrates $1 \mathbf{a}$ and $2 \mathbf{2}$ was examined under continuous recycle mode conditions (Fig. 1), where a mixture of the substrates in toluene was pressurised and passed through a heated cartridge containing $1 \mathrm{wt} \% \quad \mathrm{Au} / \mathrm{TiO}_{2}$ 30 in a packed bed. The mixture of substrates and product(s) was collected in a reservoir and then re-circulated through the system. By separating the bulk of reactants from the catalyst, the system can be rendered inherently safe by containing the reaction zone, operating under high temperatures and 35 pressures, within a small reactor volume $(<1 \mathrm{~mL})$. The system also allows for easy access to the reaction mixture for reaction progress analysis using a range of online and offline tools.

\section{Effect of temperature}

40 Applying a pressure of 50 bar to maintain a single-phase flow, a marked improvement in conversion and selectivity for $\mathbf{4 a}$ was observed when increasing the reaction temperature from 130 through 150 to $180{ }^{\circ} \mathrm{C}$ (Table 2, entries 1-3). Furthermore, by adopting nearly equimolar equivalents of the reactants at a 45 higher concentration and lower catalytic loading, the reaction proceeded smoothly to completion with extremely high selectivity for the formation of the secondary amine $\mathbf{4 a}$ - with less than $3 \%$ of byproduct being formed (entry 4).

As a comparison, the same reaction mixture and the ${ }_{50} \mathrm{Au} / \mathrm{TiO}_{2}$ catalyst was subjected to reflux under an $\mathrm{N}_{2}$ atmosphere at ambient pressure. Under these conditions, only $35 \%$ conversion of the aniline, and $68 \%$ selectivity for $\mathbf{4 a}$ can be achieved, broadly in line with the earlier report (Table 1, entry 6).

55 Hence, by expanding the reaction space, the effectiveness of a gold catalyst can be significantly enhanced, in terms of turnover and selectivity. Based on the result of the last entry of Table 2 a TOF of $c a .37 \mathrm{~h}^{-1}$ can be derived, which is broadly compatible, if not better, than other reported homo60 and hetero-geneous catalytic systems. The efficiency of the system is also accompanied by its practicality - high selectivity for the amine can be obtained with the reaction mixture left exposed to air over the course of the reaction, i.e. the need for rigorously anaerobic conditions, required by all ${ }_{65}$ the previous catalytic systems, is not necessary in this system.

Table 2 Reactions between 1a and 2a using $\mathrm{Au} / \mathrm{TiO}_{2}$ under flow conditions. ${ }^{a}$

\begin{tabular}{ccccccc}
\hline entry & $\mathrm{T} /{ }^{\circ} \mathrm{C}$ & $\mathbf{1 a}: \mathbf{2 a} / \mathrm{M}$ & {$[\mathrm{Au}] / \mathrm{mol} \%$} & $\mathrm{t} / \mathrm{h}$ & conv./\% & $\mathbf{3 : 4 a}: \mathrm{PhCHO}$ \\
1 & 130 & $0.29: 0.16$ & 2.7 & 7 & 65 & $27: 65: 8$ \\
2 & 150 & $0.29: 0.16$ & 2.7 & 4 & $>99$ & $0: 94: 6$ \\
3 & 180 & $0.16: 0.16$ & 2.7 & 1 & $>99$ & $0: 93: 7$ \\
4 & 180 & $0.51: 0.5$ & 0.9 & 3 & 99 & $<2: 97:<1$
\end{tabular}

${ }^{a}$ Reaction conditions: A mixture of $\mathbf{1 a}, \mathbf{2 a}$ and dodecane $(0.35 \mathrm{~mL}$, internal standard) in toluene $(10 \mathrm{~mL})$ was circulated through a heated 70 cartridge of $1.5 \mathrm{wt} \% \mathrm{Au} / \mathrm{TiO}_{2}$, at a flow rate of $1.5 \mathrm{~mL} / \mathrm{min}$ (residence time $=27 \mathrm{~s}$ ), 50 bar pressure. ${ }^{b} \mathrm{GC}$ conversions based on aniline.

\section{Substrate scope}

The potential application of the catalytic flow system is 75 demonstrated by conducting a small substrate screen with a selection of primary and secondary alcohols and amines (Table 3). Electron-rich and electron-poor substituents on benzyl alcohol (entries 1-3) and aniline (entries 4 and 5) can be introduced, with very high conversions achieved in just a 80 few hours. The reaction of benzyl alcohol and optically pure $\alpha$-methylbenzylamine (2c) proceeded very smoothly to give the substituted product $\mathbf{4 f}$ with complete retention of stereochemistry (entry 6). 
Table 3. Scope of gold-catalysed alkylation of amine by alcohols. ${ }^{a}$

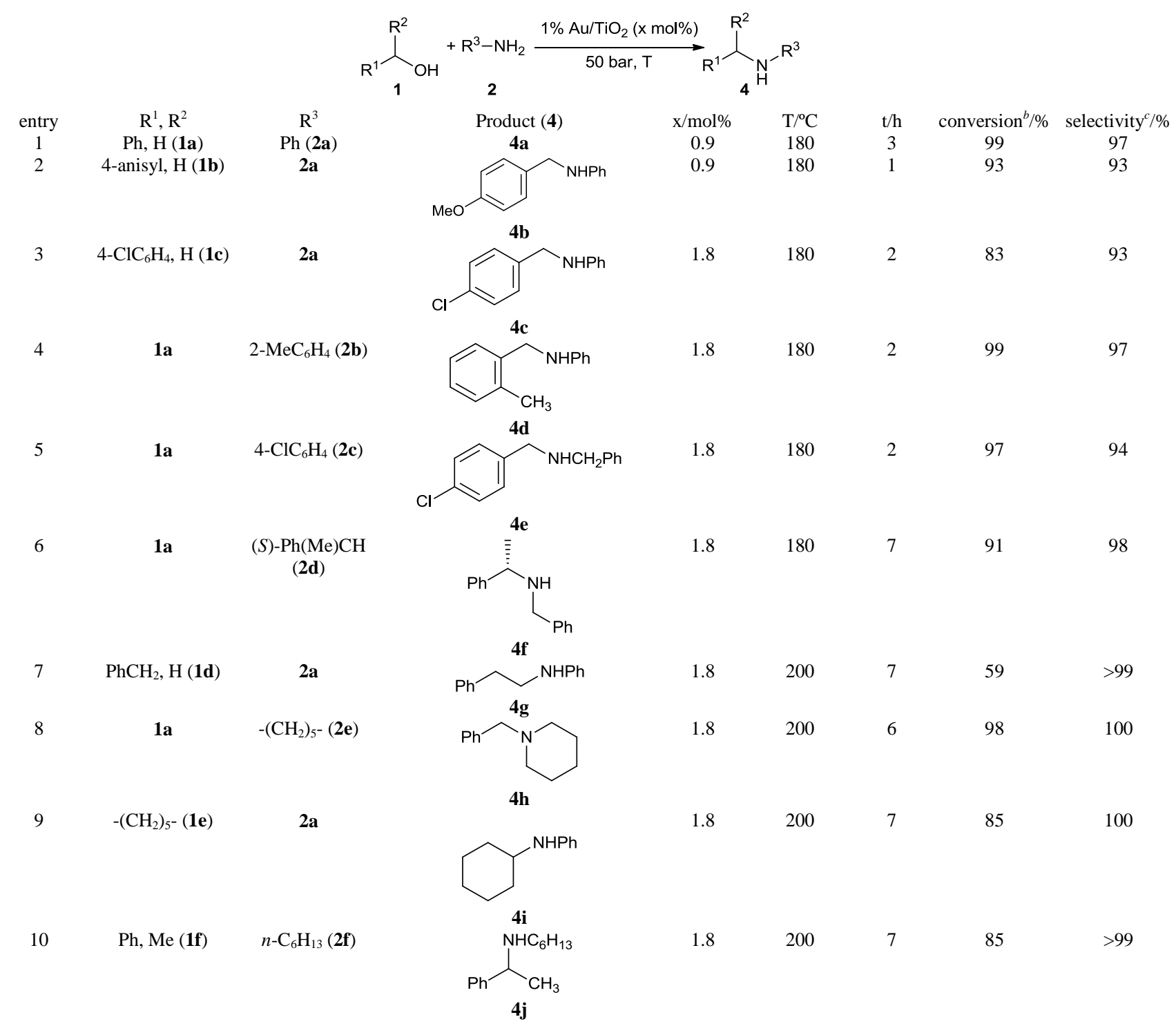

${ }^{a}$ Reaction conditions: amine $(0.5 \mathrm{M})$, alcohol $(0.5 \mathrm{M}), 0.9-1.8 \mathrm{~mol} \% \mathrm{Au}$, toluene $(10 \mathrm{~mL}), 50 \mathrm{bar}, 1.5 \mathrm{ml} / \mathrm{min}(\tau=27 \mathrm{~s}) .{ }^{b}$ Determined by GC, using dodecane as internal standard. ${ }^{c}$ Determined by ${ }^{1} \mathrm{H}$ NMR. ${ }^{d}$ Product is enantiomerically pure, as determined by chiral HPLC.

5 For less activated substrates (entries 7-10), good conversions can be obtained by increasing the temperature to $200{ }^{\circ} \mathrm{C}$; excellent selectivities can be achieved with an aliphatic alcohol (entry 7), a secondary amine (entry 8), as well as cyclic and acyclic secondary alcohols (entries 9 and 10 10). ICP analyses of crude reaction mixtures did not reveal any detectable metal content $(<0.02 \mathrm{ppm})$, thus catalyst leaching does not occur under these conditions.

The synthetic utility of the system is also demonstrated for more complex substrates by the synthesis of Piribedil $\mathbf{4 k}$, a 15 piperazine-pyrimidine derivative used in the treatment of Parkinson's disease. ${ }^{25}$ A solution of piperonyl alcohol $\mathbf{1 g}$ and 1-(pyrimidin-2-yl)-piperazine $\mathbf{2 g}$ in toluene was circulated through the heated catalyst maintained at $200{ }^{\circ} \mathrm{C}$ and 50 bar (Scheme 3). After $24 \mathrm{~h}$, the reaction mixture was simply 20 evaporated and the residue recrystallised from ethanol-water to furnish the desired product in $77 \%$ yield with high purity, without the need for column chromatography.<smiles>O=S(=O)(O)c1ccc2c(c1)OCO2</smiles><smiles>CO[AsH2]c1ncccn1</smiles>
(i) $1 \mathrm{wt} \% \mathrm{Au} / \mathrm{TiO}_{2}(1.8 \mathrm{~mol} \% \mathrm{Au})$ 50 bar, $200^{\circ} \mathrm{C}, 24 \mathrm{~h}$ (ii) Recrystallisation $\left(\mathrm{EtOH}-\mathrm{H}_{2} \mathrm{O}\right)$

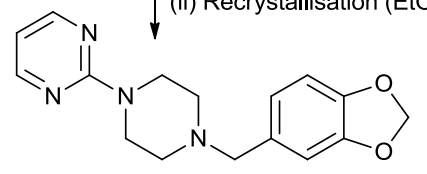

4k, $77 \%$ (79\% conversion)

Scheme 3 Synthesis of Piribedil $4 \mathbf{k}$ by direct alkylation of piperazinepyrimidine derivative $\mathbf{2 g}$ by $\mathbf{1 g}$. 


\section{Reaction mechanism}

The reaction between benzyl alcohol and aniline was analysed in our preliminary kinetic/mechanistic study. Remarkably, the selectivity and rate of the reaction are unaffected by applying 5 pressures of between 5-100 bars (Fig. S4, Supplementary Information). This implies that nascent $\mathrm{H}_{2}$ is not present in the system, i.e. reduction of the $\mathrm{C}=\mathrm{N}$ bond occurs exclusively through adsorbed hydrides. In contrast, reaction temperature has a dramatic effect on the selectivity of the reaction: A 10 significant accumulation of imine and benzaldehyde was observed at lower temperature $\left(130{ }^{\circ} \mathrm{C}\right)$, which was suppressed when the reaction temperature was raised to 150 or $180{ }^{\circ} \mathrm{C}$ (Fig.'s 2a, b and c).

A closer examination of the reaction profile revealed that 15 the presence of imine $\mathbf{3}$ was observed in the initial stages of all three reactions. At the lower reaction temperature $\left(130^{\circ} \mathrm{C}\right)$, the concentration of this oxidised products (imine and aldehdye) continues to rise over the course of the reaction. In contrast, at higher temperatures, the formation of the imine 20 ceased to be competitive, and started to behave as a reaction intermediate (Fig. 2d).

A catalytic cycle was thus proposed based on these observations, from which four rate equations can be derived. The competitive processes leading to the formation of the 25 imine byproduct is represented by two equilibria $K_{A}$ and $K_{B}$, associated with the desorption of the aldehyde from the catalyst surface, and the subsequent condensation reaction, respectively (Scheme 4). The reaction progress curves obtained under different reaction conditions (Fig.s 2a, b and c)

30 were subjected to kinetic analysis, using the model developed (in Berkeley Madonna ${ }^{26}$ ), and the results are summarised in Table 4.
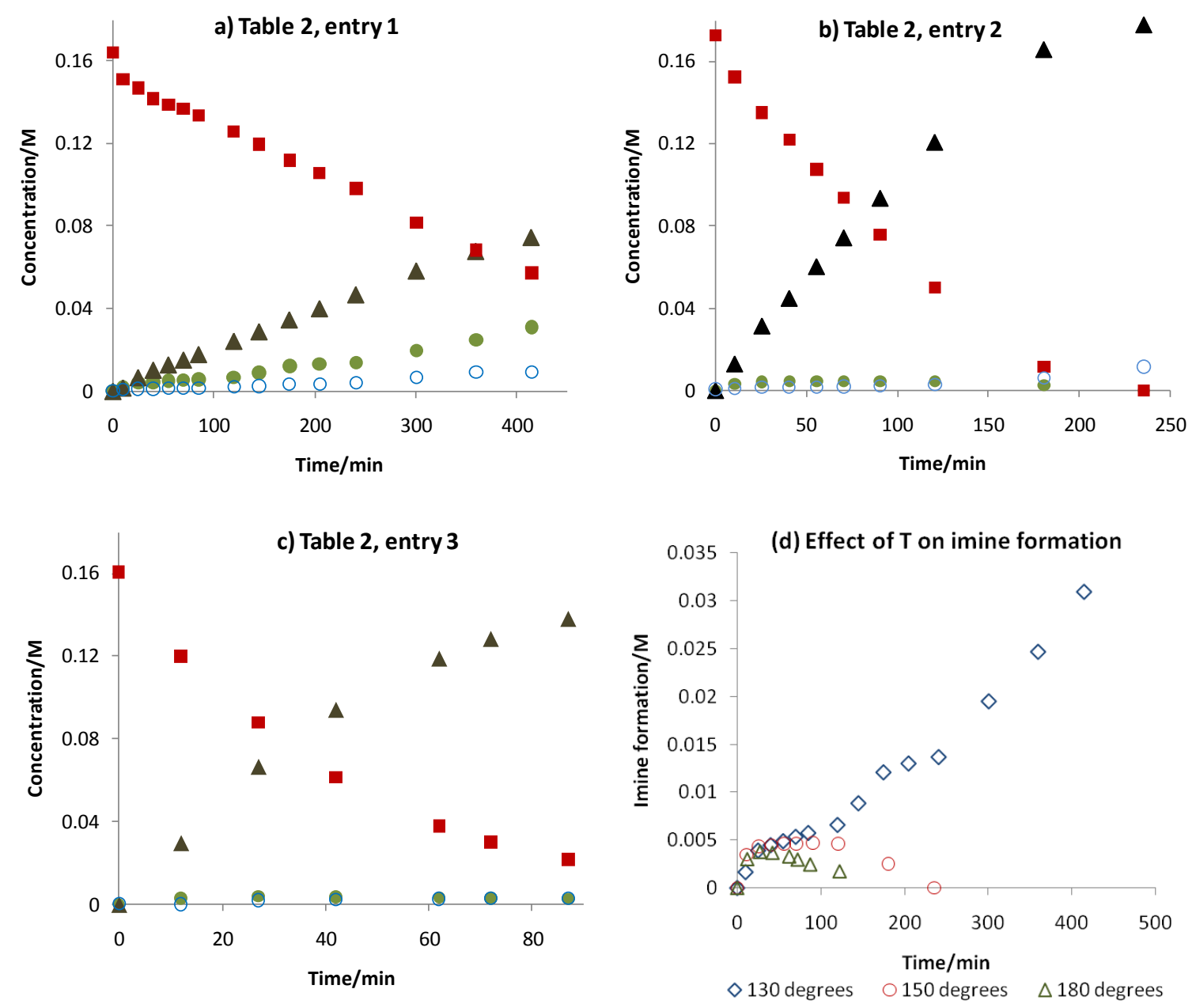

35 Fig. 2 a), b) and c) Temporal reaction profiles between 1a and 2a corresponding to entries in Table $2(\boldsymbol{\square}=[\mathbf{2 a}], \bigcirc=[\mathbf{3}], \mathbf{\Delta}=[4 \mathrm{a}], \mathrm{O}=[\mathrm{PhCHO}]) ;$ and d) Effect of temperature on the temporal evolution of imine 3 . 


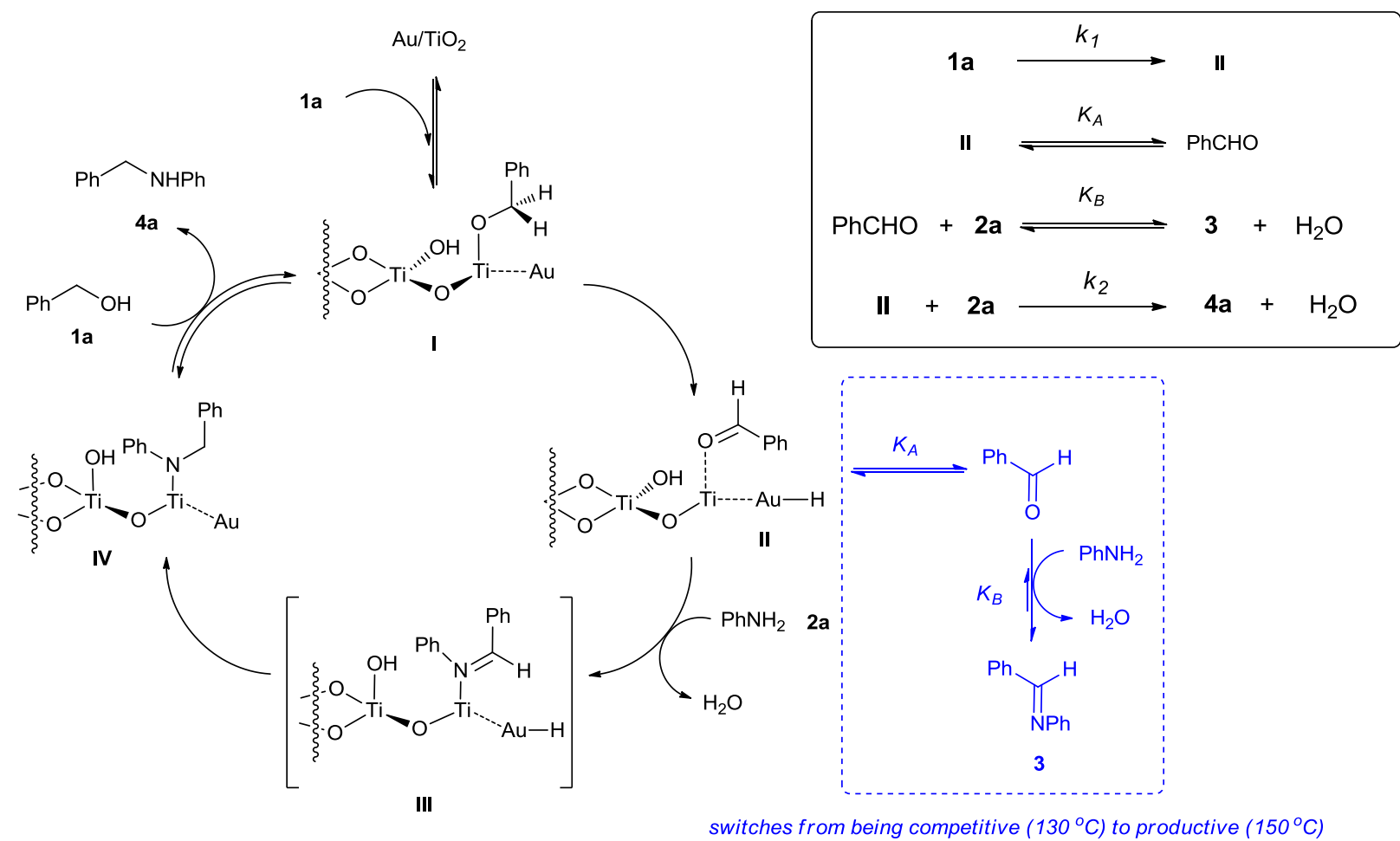

Scheme 4 Proposed catalytic cycle and associated rate equations.

Table 4. Kinetic and thermodynamic parameters derived from data fitting. ${ }^{a}$

\begin{tabular}{cccc}
$\mathrm{T} /{ }^{\circ} \mathrm{C}$ & $k_{1} / \mathrm{s}^{-1}$ & $K_{A} \cdot K_{B}$ & $k_{2} / \mathrm{M}^{-1} \mathrm{~s}^{-1}$ \\
130 & $2.05 \times 10^{-5}$ & $6.96 \times 10^{-2}$ & $3.58 \times 10^{-2}$ \\
150 & $8.61 \times 10^{-5}$ & $3.78 \times 10^{-1}$ & 0.1 \\
180 & $4.53 \times 10^{-4}$ & 1.46 & $5.65 \times 10^{-2}$ \\
$E_{a} / \mathrm{kJ} \mathrm{mol}^{-1}$ & 93.7 & 91.2 & - \\
${ }^{a}$ See Supplementary Info. & & \\
\hline
\end{tabular}

The conversion of benzyl alcohol to benzaldehyde catalysed by $\mathrm{Au} / \mathrm{CeO}_{2}$ had been extensively studied previously in a body of work by Corma and co-workers, ${ }^{27}$ whereby benzyl alcohol undergoes fast and reversible binding 10 to the catalyst surface to give an alkoxide species (I). In the present system, Langmuir-Hinshelwood type saturation kinetics was also observed, where the rate-limiting step is found to be the formation of the benzaldehyde $\left(k_{l}\right)$, with an activation energy of $93.7 \mathrm{~kJ} / \mathrm{mol}$. In all three cases, the initial 15 oxidation of the alcohol to the carbonyl compound is the ratelimiting step of the catalytic cycle.

Slow $\beta$-hydride elimination occurs to generate II, consisting of gold-hydride and surface-bound benzaldehyde, which may be liberated into solution. Condensation with 20 aniline gives adsorbed or free imines III or $\mathbf{3}$, respectively. In our proposed model, only adsorbed imine III can be reduced by $\mathrm{Au}-\mathrm{H}$ to the desired product 4a. The rate of the hydrogenation step $\left(k_{2}\right)$ is found to be at least two orders of magnitude faster than the dehydrogenation of the alcohol, and 25 is likely to be irreversible. This is supported by the observation that the stereochemistry of a chiral amine substrate can be retained during the process (Table 2, entry 6). The selectivity of the reaction is defined by the relative ratio of amine (4a) to imine (3), formed through the partitioning of
30 reaction pathway via the common intermediate II. This is dependent upon the overall rate of conversion of II to $4 \mathbf{a}\left(k_{2}\right)$, and the rate of formation of imine $\mathbf{3}$ from the desorbed benzaldehyde, expressed by a combination of two equilibrium constants $\left(K_{A} \cdot K_{B}\right)$. At $130{ }^{\circ} \mathrm{C}, k_{2}$ is sufficiently slow, such that 35 the favourable formation of the imine $\left(K_{A} \cdot K_{B}=6.96 \times 10^{-2}\right)$ is competitive. At higher temperatures, imine formation becomes disfavoured, particularly at higher conversions (where the amount of water in the system increases). This effectively counteracts the desorption process by increasing 40 the amount of benzaldehyde in the system, thus allowing it to re-enter the productive catalytic cycle. At $180{ }^{\circ} \mathrm{C}$, very high selectivity can be achieved, even though the process is dominated by the larger $K_{A} \bullet K_{B}$ equilibria. It is interesting that $k_{2}$ appear to decrease when the temperature was raised from 45150 to $180{ }^{\circ} \mathrm{C}$. It is important to keep in mind that $k_{2}$ embraces several key bond-forming steps (formation of imine, reduction and liberation from the surface), and this break from the Arrhenius linearity suggests there may be a change in the mechanism of at least one of these steps.

50

\section{(Unexpected) Effect of water}

Given that water is generated as a by-product of this process, it is not unreasonable to assume that the removal of water can have a beneficial effect on the process. With this in mind, 55 further experiments were conducted under anhydrous conditions; with a sample of a catalyst dried in an oven overnight at $150{ }^{\circ} \mathrm{C}$, and by passing the reaction stream through a cartridge of molecular sieves. Rather surprisingly, catalyst activity and selectivity were practically annihilated 60 under these conditions (Fig. 3) - only 10\% conversion was 
achieved after $3 \mathrm{~h}$ with $29 \%$ selectivity for the amine product. It is notable that even the formation of benzaldehyde was sequestered under these conditions, i.e. water plays a crucial role in activating the catalyst at the onset of the reaction. The 5 interaction between water and $\mathrm{TiO}_{2}$ is key to several important energy and environmental applications (e.g. solar-hydrogen production and photodecomposition of organic pollutants). As the subject of numerous studies over the last few decades, ${ }^{28}$ it is generally accepted that water can dissociate over certain $10 \mathrm{TiO}_{2}$ surfaces to generate $-\mathrm{OH}$ and $-\mathrm{H}$ species which affects its acid-base properties. Very recently, the interaction of alcohols with $\mathrm{TiO}_{2}$ surfaces has also been investigated at the solid-liquid boundary. ${ }^{29}$ Hence, we postulated that the presence of water is critical in the activating the surface of $15 \mathrm{TiO}_{2}$ towards adsorption of substrates that are critical for catalytic activity.

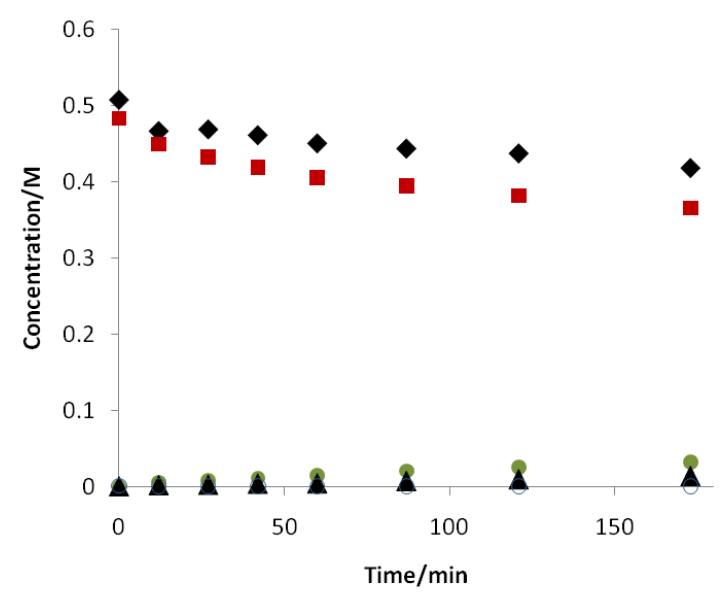

Fig. 3 Reaction between $1 \mathbf{a}$ and $\mathbf{2 a}$ under anhydrous conditions $(\boldsymbol{\square}=[\mathbf{2} \mathbf{a}]$, $=[3], \boldsymbol{\Delta}=[4 \mathrm{a}], \bigcirc=[\mathrm{PhCHO}])$. Reaction conditions: $180^{\circ} \mathrm{C}, 50$ bar, 20 $1.5 \mathrm{~mL} / \mathrm{min}, 1 \mathrm{~mol} \% \mathrm{Au} / \mathrm{TiO}_{2}$.

\section{Conclusions}

The use of gold as a viable heterogeneous catalyst for the alkylation of amines by alcohols has been achieved for the first time under aerobic conditions using a continuous flow 25 reactor and commercially-available catalysts that are otherwise not selective in batch reactors. ${ }^{30}$ Very high reactivity and selectivity can be accomplished in several systems.

Compared to previously reported systems, the gold30 catalysed flow process has a number of notable advantages:

(i) Catalysis occurs entirely at the surface of $\mathrm{Au}-\mathrm{TiO}_{2}$, and there is no detectable leaching;

(ii) Unlike all other catalysts, rigorous exclusion of air and/or moisture is not necessary;

35 (iii) Reactions can be performed using commercially-available catalyst from several sources;

(iv) Equimolar amounts of the reactants can be used, and addition of exogenous base is not necessary; thus greatly simplifying product purification; and

40 (v) The system allows for easier and safer scale-up of processes.

Key steps of the catalytic cycle have been elucidated by kinetic modelling. The study show that the inherent lower catalytic activity of the gold catalyst can be overcome by 45 adopting a higher reaction temperature $\left(>150^{\circ} \mathrm{C}\right)$ afforded by a flow system, where the formation of imine become reversible and can re-enter the productive catalytic cycle.

The current study also uncovered a possible change in reaction mechanism at $180{ }^{\circ} \mathrm{C}$, and an unexpected role of 50 water in the activation of the catalyst. These will be investigated further. Modifications of the catalyst will also be attempted, to further improve its efficiency, including widening of the reaction scope to a broader range of substrates.

\section{${ }_{55} 4$ Experimental}

\section{General}

Starting materials were procured commercially and used without purification. Reactions were performed in reagent grade toluene. The conversion of alcohols to products was 60 monitored using a HP6890 gas chromatography system fitted with an SPB-5 column (30 $\mathrm{m} \times 0.2 \mu \mathrm{m} \times 0.8 \mu \mathrm{m})$. The percentage of conversion/selectivity was determined by comparison with known standards, using a calibration plot for product and reactant, against dodecane as an internal standard. ${ }_{65}$ The identity of all products was further verified by comparison of their ${ }^{1} \mathrm{H}$ NMR spectra to that reported, recorded in $\mathrm{CDCl}_{3}$ using a Bruker Avance NMR spectrometer at 400 $\mathrm{MHz}$. ICP analyses (\% Au) were performed using a PerkinElmer 2000 DV ICP-OE spectrometer. The BET surface area 70 and mean pore size of the catalyst were obtained by low temperature $\mathrm{N}_{2}$ adsorption studies at $77 \mathrm{~K}$ using a Micromeritics Tristar 3000 instrument.

\section{Catalyst characterisation}

$1 \mathrm{wt} \% \mathrm{Au} / \mathrm{TiO}_{2}$ obtained from Strem (AUROlite ${ }^{\mathrm{TM}} \mathrm{Au} / \mathrm{TiO}_{2}$ ), 75 was grounded in a mortar and pestle and sieved. Particle sizes of between 125-250 microns were employed. Average gold crystallite size is ca. $2-3 \mathrm{~nm}$. BET surface area $=40 \mathrm{~m}^{2} \mathrm{~g}^{-1}$, mean pore size $=0.26 \mathrm{~cm}^{3} \mathrm{~g}^{-1}$, mean pore diameter $=26 \mathrm{~nm}$.

\section{Catalytic reactions}

${ }_{80}$ Reactions were performed using a ThalesNano X-Cube ${ }^{\mathrm{TM}}$ flow reactor. ${ }^{31} \mathrm{~A}$ solution of the alcohol $(0.29 / 0.5 \mathrm{M})$ and amine $(0.16 / 0.5 \mathrm{M})$ in toluene $(10 \mathrm{~mL})$ containing dodecane $(0.18 \mathrm{M})$ as an internal standard, was (re)circulated through a heated cartridge containing $1 \mathrm{wt} \% \mathrm{Au} / \mathrm{TiO}_{2}(0.6-1.8 \mathrm{~g})$ at $180-$ ${ }_{85} 200{ }^{\circ} \mathrm{C}$, under an applied pressure of between 5-100 bars. The progress of the reaction was monitored by GC analysis. Upon completion, the solution was evaporated to afford the corresponding substituted amine with $>90 \%$ recovery. The purity and identity of the product were verified by ${ }^{1} \mathrm{H}$ NMR 90 spectroscopy (Supplementary Information).

\section{Synthesis of Piribedil (4k)}

A mixture of the alcohol $\mathbf{1 g}(760 \mathrm{mg}, 5 \mathrm{mmol})$ and piperazine $2 \mathrm{~g}$ (827.4 mg, $5 \mathrm{mmol})$ in toluene $(10 \mathrm{~mL})$ was circulated for $24 \mathrm{~h}$ through $1.8 \mathrm{~mol} \%$ of $\mathrm{Au} / \mathrm{TiO}_{2}$ mounted in 2 heated ${ }_{95}$ cartridges, held at $200{ }^{\circ} \mathrm{C}$ and 50 bar pressure. The reaction 
mixture was evaporated to dryness, and the residue was recrystallised from hot EtOH- $\mathrm{H}_{2} \mathrm{O}$, to give the desired product as a buff-colour solid (1.15 g, 77\%). ${ }^{1} \mathrm{H} \quad \mathrm{NMR}$ data (Supplementary Information) is in accordance with reported 5 values. $^{32}$

\section{Acknowledgements}

The work is funded by an EPSRC grant for Flow Chemistry (EP/G027544/1), with additional support by Pfizer Inc. We thank the Pharmacat Consortium for useful discussions.

\section{${ }_{10}$ Notes and references}

${ }^{a}$ Department of Chemistry and ${ }^{b}$ Department of Chemical Engineering and Chemical Technology, Imperial College London, Exhibition Road, South Kensington, London SW7 2AZ, U.K.; E-mail (corresponding authors): k.hellgardt@imperial.ac.uk; mimi.hii@imperial.ac.uk

$15{ }^{c}$ Pfizer Global Research \& Development, Ramsgate Road, Sandwich CT13 9NJ, U.K

$\dagger$ Electronic Supplementary Information (ESI) available: Details of kinetic analysis and fitted curves, pressure effects, Arrhenius plots, and ${ }^{1} \mathrm{H}$ NMR spectra of products. See DOI: 10.1039/b000000x/

20

1. P. A. Wender, V. A. Verma, T. J. Paxton and T. H. Pillow, Acc. Chem. Res., 2008, 41, 40-49.

2. T. Newhouse, P. S. Baran and R. W. Hoffmann, Chem. Soc. Rev., 2009, 38, 3010-3021.

253 . P. J. Dunn, A. S. Wells and M. T. Williams, eds., Green Chemistry in the Pharmaceutical Industry, Wiley-VCH, 2010.

4. D. J. C. Constable, P. J. Dunn, J. D. Hayler, G. R. Humphrey, J. L. Leazer, R. J. Linderman, K. Lorenz, J. Manley, B. A. Pearlman, A. Wells, A. Zaks and T. Y. Zhang, Green Chem., 2007, 9, 411-420.

305 . T. D. Nixon, M. K. Whittlesey and J. M. J. Williams, Dalton Trans., 2009, 753-762.

6. G. Guillena, D. J. Ramon and M. Yus, Chem. Rev., 2010, 110, 16111641.

7. F. Shi, M. K. Tse, X. J. Cui, D. Gordes, D. Michalik, K. Thurow, Y.

35 Q. Deng and M. Beller, Angew. Chem. Int. Ed., 2009, 48, 5912-5915.

8. A. Martinez-Asencio, D. J. Ramon and M. Yus, Tetrahedron Lett., 2010, 51, 325-327.

9. Y. Zhao, S. W. Foo and S. Saito, Angew. Chem. Int. Ed., 2011, 50, 3006-3009.

40 10. J. L. He, J. W. Kim, K. Yamaguchi and N. Mizuno, Angew. Chem. Int. Ed., 2009, 48, 9888-9891.

11. K. Yamaguchi, J. L. He, T. Oishi and N. Mizuno, Chem.--Eur. J., 2010, 16, 7199-7207.

12. J. W. Kim, K. Yamaguchi and N. Mizuno, J. Catal., 2009, 263, $205-$ 208.

13. P. R. Likhar, R. Arundhathi, M. L. Kantam and P. S. Prathima, Eur. J. Org. Chem., 2009, 5383-5389.

14. R. Martinez, D. J. Ramon and M. Yus, Org. Biomol. Chem., 2009, 7, 2176-2181.

50 15. J. He, K. Yamaguchi and N. Mizuno, Chem. Lett., 2010, 39, 11821183.

16. X. Cui, Y. Zhang, F. Shi and Y. Deng, Chem.--Eur. J., 2011, 17, 1021-1028.

17. C. Della Pina, E. Falletta, L. Prati and M. Rossi, Chem. Soc. Rev., 2008, 37, 2077-2095.

18. L. McEwan, M. Julius, S. Roberts and J. C. Q. Fletcher, Gold Bull., 2010, 43, 298-306.

19. T. Ishida, N. Kawakita, T. Akita and M. Haruta, Gold Bull., 2009, 42, 267-274.

60 20. A. Corma, T. Rodenas and M. J. Sabater, Chem.--Eur. J., 2010, 16, 254-260.

21. H. Sun, F. Z. Su, J. Ni, Y. Cao, H. Y. He and K. N. Fan, Angew. Chem. Int. Ed., 2009, 48, 4390-4393.

22. S. Kegnaes, J. Mielby, U. V. Mentzel, C. H. Christensen and A.

65 Riisager, Green Chem., 2010, 12, 1437-1441.
23. L. He, X.-B. Lou, J. Ni, Y.-M. Liu, Y. Cao, H.-Y. He and K.-N. Fan, Chem.--Eur. J., 2010, 16, 13965-13969.

24. N. Zotova, K. Hellgardt, G. H. Kelsall, A. S. Jessiman and K. K. Hii, Green Chem., 2010, 12, 2157-2163.

70 25. M. J. Millan, Pharmacol. Ther., 2010, 128, 229-273.

26. http://www.berkeleymadonna.com/

27. A. Abad, A. Corma and H. García, Chem.--Eur. J., 2008, 14, 212222.

28. C. H. Sun, L. M. Liu, A. Selloni, G. Q. Lu and S. C. Smith, J. Mater Chem., 2010, 20, 10319-10334.

29. V. M. Sanchez, E. de la Llave and D. A. Scherlis, Langmuir, 2011, 27, 2411-2419.

30. $\mathrm{Au} / \mathrm{TiO}_{2}$ attained from other sources such as World Gold Council and donted by Johnson Matthey plc, were also found to be effective under these conditions.

31. ThalesNano Nanotechnology Inc., Graphisoft Park, H-1031 Budapest Zahony u. 7, Hungary (see: http://www.thalesnano.com/products/xcube).

32. A. J. A. Watson, A. C. Maxwell and J. M. J. Williams, J. Org. 85 Chem., 2011, 76, 2328-2331. 